\title{
Heart rate analysis during very deep dives in flooded caves: single case study
}

\author{
Marco Ivaldi ${ }^{a, *}$, Andrea Ciavattini a , Giovanni Cugliari ${ }^{b}$ \\ a University Structure of Hygiene and Sport Sciences - SUISM, University of Turin, Turin, Italy \\ b Department of Medical Sciences, University of Turin, Turin, Italy \\ *Corresponding author Email: marco.ivaldi@unito.it \\ DOI: https://doi.org/10.34256/ijpefs2032
}

Received: 18-05-2020, Accepted: 10-08-2020

Abstract: The purpose of this study is to investigate the heart rate adaptations during deep dave diving with MCCR (mechanical closed circuit rebreather). Previous studies on this matter have not been conducted to the depths reached in this study and most of them have been conducted inside hyperbaric chambers trying to recreate the immersion conditions. The data collection took place during the exploration of two hydrogeological sites by a professional cave diver. The recordings were made using a SCUBAPRO GALILEO SOL $®$ dive computer capable of monitoring the heart rate, with a sampling interval of $0,25 \mathrm{~Hz}$. The data collected confirm a direct relationship between the increase in diving depth and the increase in the detected heart rate.

Keywords: Scuba diving, Cave diving, Autonomous nervous system, Heart rate analysis.

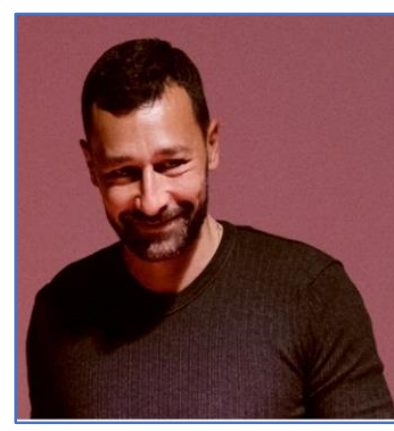

Dr. Marco Ivaldi obtained a $\mathrm{PhD}$ in complex systems in medicine and life sciences, with a specialization in medical physiopathology in 2012, after receiving the honourable badge of the Royal University of Turin (Italy) for his thesis degree. He is an adjunct professor in the department of medical science of the University of Turin (Italy) and he deals with the physiology of the exercise concerning the presence of environmental pollutants, quantitative electroencephalographic analysis, movement-related neuroscience and neuromarketing.

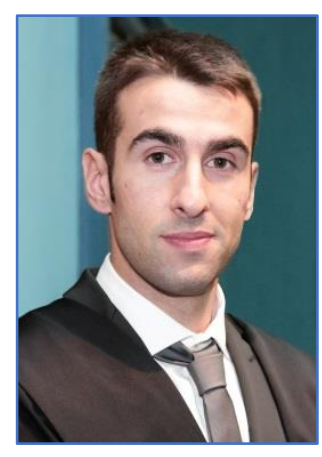

Andrea Ciavattini obtained his Sports Science degree in 2014 and his master's degree in Sports Science in 2016. He's working in the Fitness Industry as a personal trainer in Virgin Active Italy, and he's also a fitness coach and a kinesiologist. In 2018 he started his career as a
Physical education teacher.

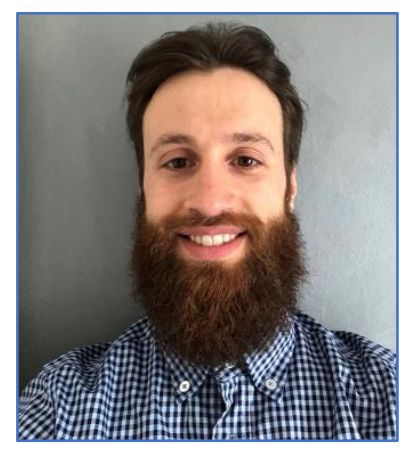

Dr. Giovanni Cugliari is a head data scientist at the Department of Medical Sciences, University of Turin. Ph.D. in Data Science, graduated in Medical Sciences and Oncology, Physics and Biostatistics. Responsible for the study design, data collection, quality control and adv. analysis of multicenter funded projects in clinical research and epidemiology.

\section{Introduction}

The purpose of this study is to investigate the heart rate adaptation induced by deep diving with MCCR (mechanical closed circuit rebreather) in flooded caves. This field has not yet been thoroughly investigated, knowledge of human diving response in this setting is therefore scarce. Most of the studies have been carried out at relatively shallow depths or in apnea [1]. Furthermore, also the variability of the heart rate only recently was analyzed, but always at 
relatively low depths $[2,3]$. In addition, the use of rebrither has been analyzed in very few cases [4]. Often in the studies conducted in the past years discordant results are found and the heart rate data is detected as a secondary parameter, through which it is possible to analyze other physiological adaptations. Much of the measurements in these studies were also conducted in conditions that attempt to simulate a real dive, such as through the use of a hyperbaric chamber, or inside a swimming pool.

In 2001 Schipke JD. and Pelzer M. [5] conducted a study aimed at identifying the effects of scuba diving on heart rate variability and to try to identify the best candidates for diving. During the study it was possible to observe a significant reduction in heart rate during diving and a consequent increase in variability. Similar heart rate reduction was found in 2011 by Walker, B. E., Tetzlaff, K. et al. [6] during open water scuba dives in children.

In 2004 Molénat F., Boussuges A. et al. [7] set themselves the goal of investigating hemodynamic and echocardiographic changes during compression in a hyperbaric chamber conducted to simulate the conditions of a dive with a respirator. Contrary to what was observed in the previous study, no significant changes in heart rate were identified.

In 2009 ChouChou F., Pichot V. et al. [8] analyzed the responses of the autonomic nervous system during the dive with the respirator through the analysis of the variability of the heart rate. In the study they observed that all indicators of the activity of the parasympathetic autonomic nervous system on cardiac variability increase, while the activity of the autonomic sympathetic nervous system decreases.

One year later, in 2010, Barbosa E., GarcíaManso JM. et al. [9] conducted another study inside a hyperbaric chamber. The study aimed to determine the effects of pressure on heart rate variation during a dive with a respirator. In the study they conducted, according to what was observed by Schipke JD. [5] and ChouChou F. [8], there was an increasing level of bradycardia and an increase in heart rate variability with increasing blood pressure. The following year, in 2011, Walker BE., Tetzlaff K. et al. [6] monitored heart rate during a dive with breathing apparatus conducted in open water. Also in this study, according to many of the previous studies, a decline in heart rate compared to the initial rate was observed.
In 2012 Hansel J., Tetzlaff K. et al. [10] conducted another study to investigate cardiac functions following simulated dives inside a hyperbaric chamber. In this study, in contrast with what stated by the majority of the studies so far examined and in accordance with the research conducted by Molénat $F$., Boussuges A. et al. [7] it has been observed that simulated immersion in a sealed chamber does not induce significant changes in heart rate.

In 2013 Marabotti C., Scalzini A. et al. [11] evaluated cardiovascular adaptations during scuba diving. In this study, a phenomenon not yet found by any of the studies examined previously was observed: the phenomenon of bradycardia was observed after the conclusion of the dives, while during the dives no significant changes in heart rate were observed. The same researchers in the conclusions of their study say that this may have been caused by the experimental situation.

Finally in 2014, when Bosco G., De Marzi E., et al. [12] decided to conduct a study to demonstrate the usefulness of a twelve-channel holter analyzer under water. In this study, the heart rate during the dive was consistently over the basal rate with minimal variation and a marked bradycardia was observed during the post-dive, in accordance with what was observed by Marabotti C., Scalzini A. et al., [11]. Starting from what has been possible to observe thanks to past studies we have tried to clarify the nature of the adaptations in heart rate in relation to the depth of immersion. While in almost all the studies analyzed, the tests were conducted at depths often not exceeding twenty-five meters, this study aims to analyze the adaptations of heart rate at very high depths, specifically during cave diving at depths ranging from 99 to over 200 meters.

The measurements were made possible thanks to the collaboration of an expert diver, the deep diver Luigi Casati, who can boast years of experience and thousands of performed dives. This study is part of the activity that the authors are carrying out on human physiology in extreme environments or in extreme performances [13].

\section{Materials And Methods 2.1 Cave diving}

Diving in flooded caves is a specific activity of the underwater speleology, that arises from the union between a dry activity, speleology, and an activity practiced underwater. 
Athletes practicing this discipline dive inside caves or underground springs entirely filled with water, the exploration of which would be impossible without the aid of a respirator and appropriate equipment.

Cave diving, in addition to the purely sporting aspect linked to the dive itself, implies the knowledge by divers of notions concerning the geological, biological, hydrological study and the karst environment. It is in fact an activity much more linked to the scientific environment rather than to the sports one, and it involves the collection of data and material for the mapping of caves and siphons.

The topography allows for precise information on the direction and inclination of the cave; each exploration is accompanied by photos and videos collected during the dive. Through the scientific processing of these data it is possible to get to know the morphology of the entire system.

Cave diving can be considered an extreme sport as diving, once reached a certain depth, is often conducted in solitude, also because of the very narrow spaces that often have to be faced inside the caves. At high depths, any inconvenience, such as a malfunction of some equipment, could be very risky for the athlete's safety.

Cave diving is much more physiologically demanding than diving in open waters, since the siphons making up the caves do not have a regular downward course. In these environments, we often find ourselves facing downhill sections interspersed with flat or rising sections, which can be extended for hundreds of meters and divided into multiple tunnels.

For an inexperienced person this can easily result in a loss of orientation, a very dangerous scenario during an exploration. Another variable that should not be underestimated is the current, it can undoubtedly vary depending on the weather conditions, but normally the diver gets into the siphon swimming against the current, sometimes needing to anchor himself to the rocks during the narrow passages, helping himself with the hands so as not to risk being transported to the entrance.

The motivations that push the cave diver are often the curiosity to go into places where no man has been before them discovering what is beyond, testing their physical and psychological limits in doing so (Figure 1).

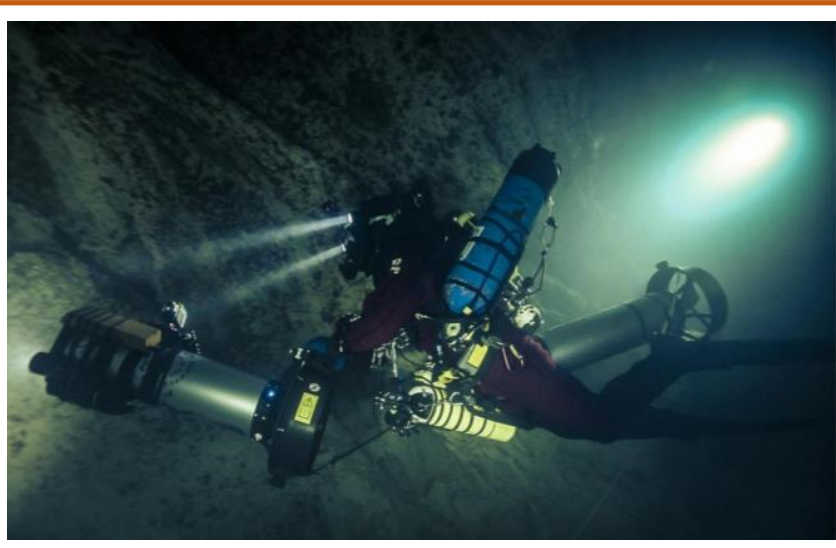

Figure 1. Luigi Casati during the exploration of the source of the Gorgazzo. (Photo courtesy of Digitalmovie Photography and Videography).

\subsection{Athlete}

The athlete is a 51-year old male cave diver with 38 years of diving experience, 32 years of speleological experience and multiple diving certification. During his activity he dives in over 2000 cave dives, of which 1200 carried out with the prospect of exploring new environments in a hundred different caves. Seventy of these dives were made over 140 meters deep in the cave. In 2008 the diver reached 212 meters deep at a distance of 440 meters from the cave entrance of Gorgazzo (Italy), thus obtaining an Italian record regarding the depth of immersion in the cave.

\subsection{Sources}

Heart rate was measured during 8 dives in two different sources: Gorgazzo (Italy) and Vrelo Une (Croatia). The source of the Gorgazzo (Figure 2) is a cave from which the stream of the same name flows, a tributary of the Livenza river, located near Polcenigo (Pordenone, Italy). The cave is made up of one of the deepest springs ever explored in the world, being the second deepest siphon karst spring in Europe.

This particular type of source is formed due to the permeability of the materials that can be found in the ground which allow rain and river waters to penetrate deep into the subsoil, forming a water table. The water then re-emerges from the subsoil in correspondence with waterproof materials thus forming the source of a river which instead of coming out from the top of a mountain, flows from the bowels of the earth. The source of the Gorgazzo is not a permanent source, it is instead called by the locals a "source of overflow": the water to escape into the stream only when the supply of the aquifer allows the maximum 
capacity to be exceeded and causes the rise of waters inside the siphon.

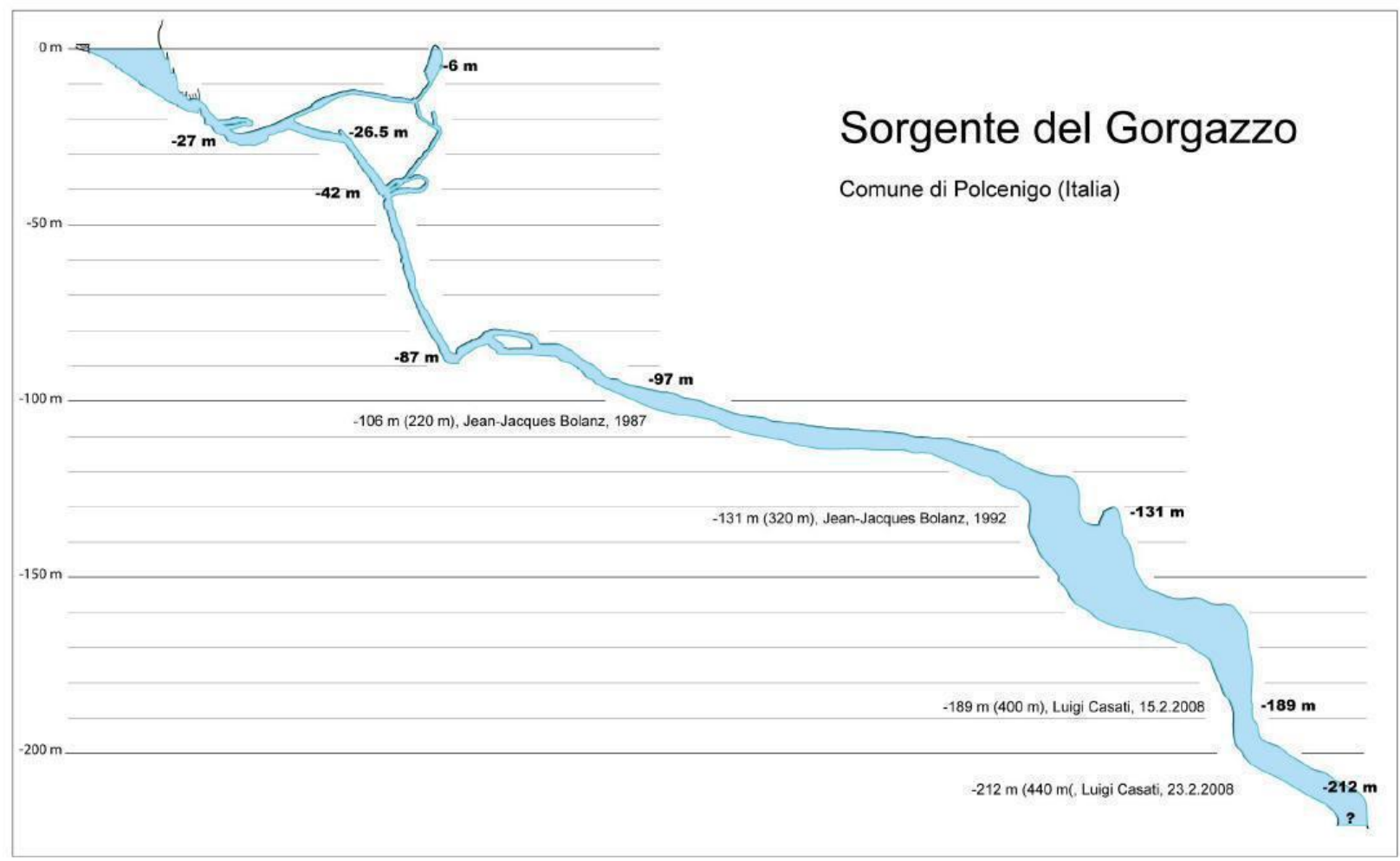

Figure 2. Topographical map of the source of the Gorgazzo.

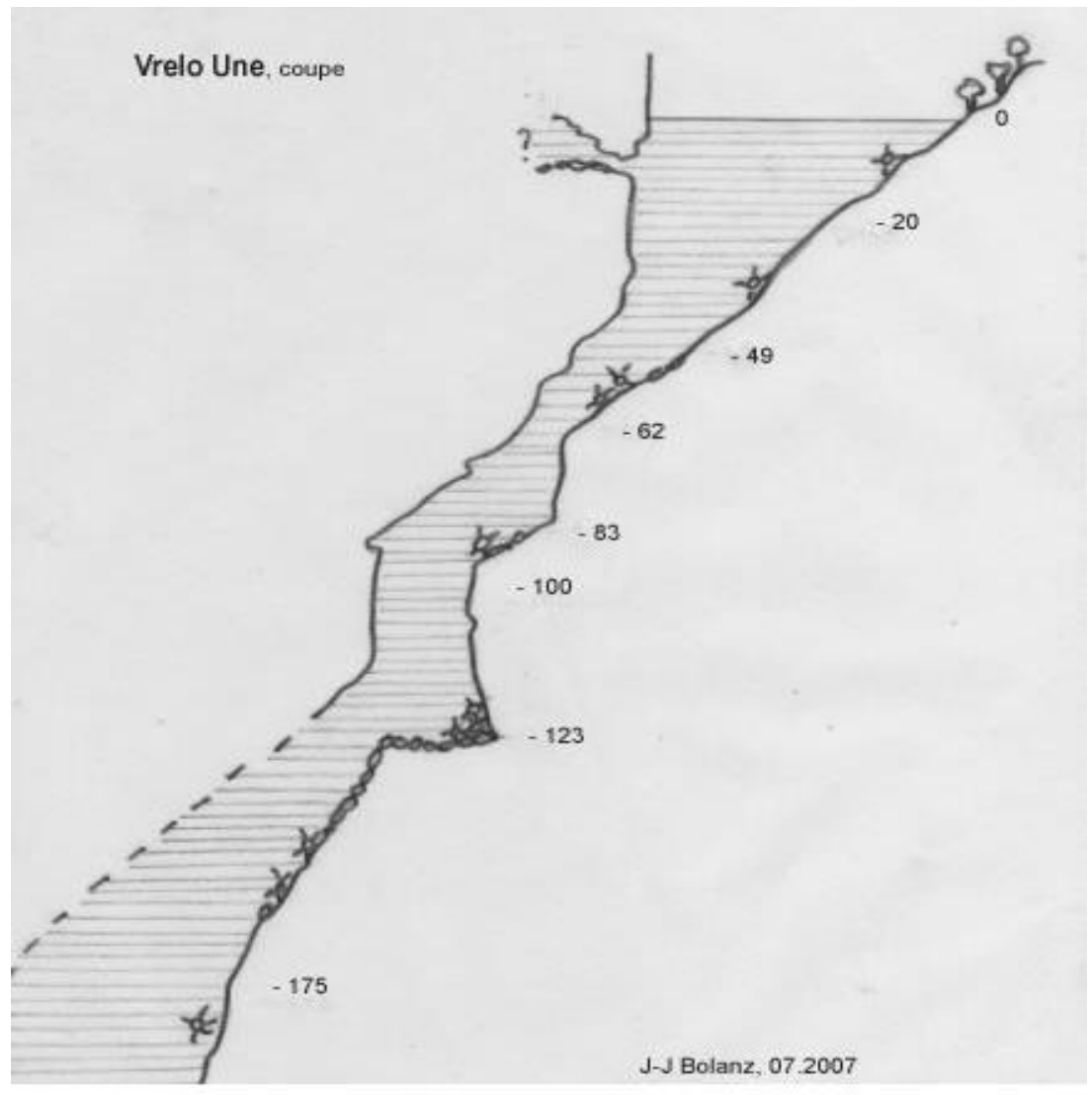

Figure 3. Topographic map of the source of Vrelo Une. 
The source of Vrelo Une (Figure 3 ) is located in Croatia, at the foot of the Stražbenica mountain. From this source originates the river Una, which flows through the northwestern region of Bosnia and Herzegovina. This source has many similarities with that of the Gorgazzo in that it is also a karst spring with a siphon.

\subsection{Equipment}

Deep cave diving is an event lasting many days and involving a significant number of expert divers to transport the equipment to the exploration site. It is important to choose the period in which the dive will be carried out, since the success of the latter is closely related to the weather conditions that can significantly influence the currents that oppose the descent inside of the caves.

Exploration requires a significant amount of time and effort also with regard to the preparation and positioning of the equipment.

In the days preceding the dive, the support group makes several dives inside the cave to depths that have already been explored. During these dives the group's task is to place all the equipment that will be needed underwater.

Given the very long duration of the dive, which can generally go up to five hours or more, there is a need to have a very large number of tanks, most of which will be positioned inside the cave, in in order to allow the chief diver to have a point where he can supply air in the immediate vicinity. The tanks can be filled with different types of oxygen mixtures and other compounds according to the different needs that will be faced according to the type of immersion.

Different wooden planks are applied to each of the cylinders, which are used to compensate for the level of floating of the cylinder. The number of axles varies according to the size and weight of the cylinder itself.

The descent into the cave takes place thanks to the use of an underwater scooter, which allows a higher speed of movement, allowing the diver to save important metabolic energies. Furthermore the scooter doesn't lift earthed deposits from the bottom of the cave that would limit the visual.

In addition to the tanks, another fundamental part of the equipment is the decompression bell. The bell is a housing inside which the diver can sit and breathe air without the need to use tanks. It is used during the ascent, when the diver needs to linger at a certain depth for an extended period which varies according to the time spent underwater and the depth reached during the dive. This step is necessary to allow the diver to perform decompression, a process that serves to allow the body to safely eliminate inert gases in order to avoid health problems, such as decompression sickness. During this break, the microbubbles of inert gas accumulated in the body during the dive are expelled through the lungs. The bell is positioned at a depth that varies from 6 to 10 meters below the water level, and is stabilized thanks to the use of concrete blocks. The expeditions involve a group of professional photographers who take care of documenting the preparation and organization of exploration through photos and videos.

\subsection{Data Collection}

The recording of heart rate data took place through the use of a SCUBAPRO GALILEO SOL $®$, a dive computer capable of monitoring the heart rate up to a depth of 330 meters with a sampling interval of $0,25 \mathrm{~Hz}$. The dive computer was worn on the wrist by Luigi Casati while diving. The GALILEO SOL $®$ is able to receive data from a POLAR $($ heart rate monitor belt that was worn by Luigi Casati underneath the diving drysuit during his explorations.

The data recorded by the dive computer were later downloaded to the computer via infrared, thanks to the software provided by the manufacturer SMARTTRAK $®$, after which it was possible to export them to $M A T L A B \otimes$ and $R \circledast$ to calculate their statistical significance (Figure 4).

\section{Results}

The following table collects the significant, physiological, environmental and performance information collected during exploration in the cave (Table 1).

\subsection{Linear regression analysis}

Linear regression analysis shows HR variation related to the increase of one unit of deep considering all divings: we found a statistically significant ( $P$ value: $<2 \mathrm{e}-16)$ variation of $0,40 \mathrm{bpm}$ considering the increase of one meter of depth (Figure 5). 


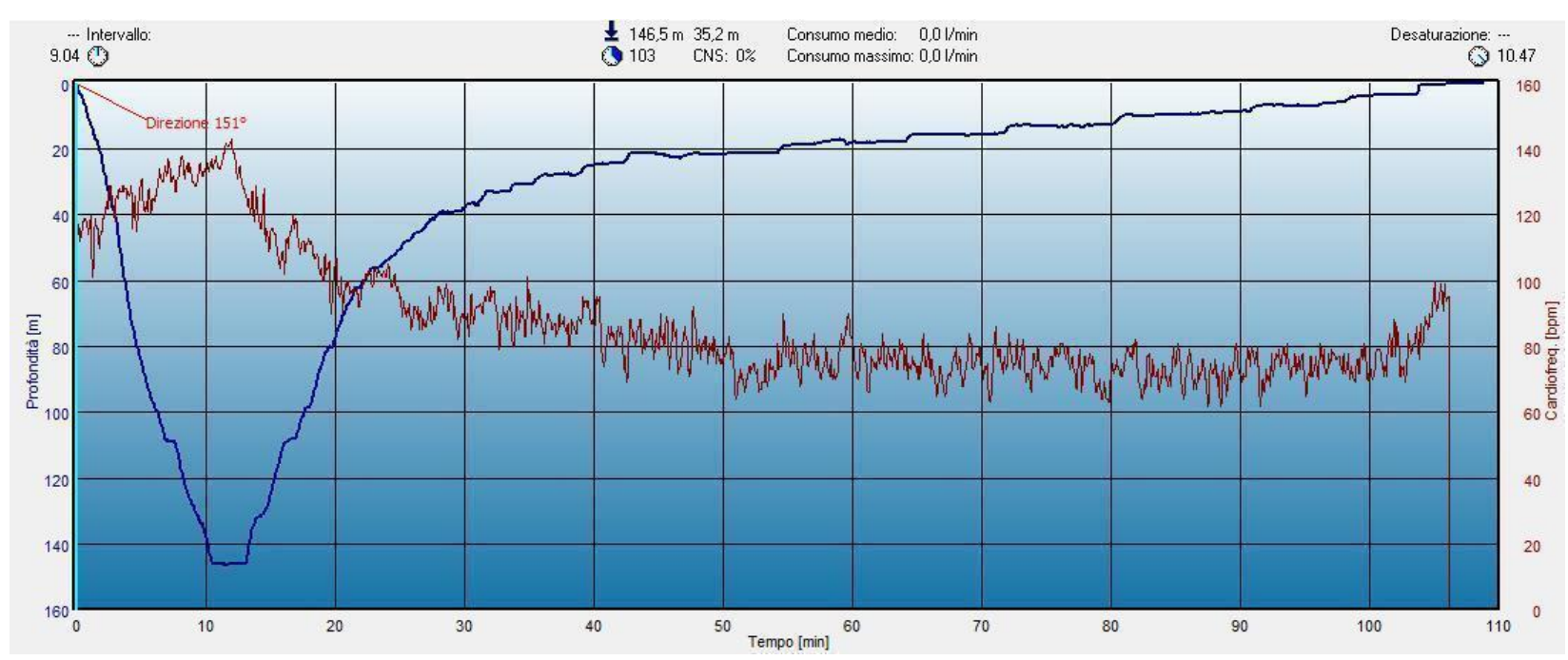

Figure 4. Example of a dive profile showing the depth data (blue line) and heart rate data (red line) in ordinate. Time is in abscissa.

Table 1 The table shows the physiological, topographical and environmental data relating to the 8 dives made in the source of the Gorgazzo and in the source of Vrelo Une.

\begin{tabular}{|c|c|c|c|c|c|c|c|c|}
\hline Source and diving number & Gorgazzo 1 & Gorgazzo 2 & Gorgazzo 3 & Gorgazzo 4 & Vrelo Une 1 & Vrelo Une 2 & Vrelo Une 3 & Vrelo Une 4 \\
\hline Dive time (s) & 7936 & 8092 & 3628 & 8300 & 6528 & 12620 & 6332 & 22584 \\
\hline Maximum depth $(\mathrm{m})$ & 134,7 & 150,32 & 99,18 & 179,38 & 151,29 & 204,71 & 149,36 & 251,67 \\
\hline Descent time (s) & 1456 & 1424 & 888 & 860 & 688 & 716 & 1032 & 836 \\
\hline Ascent time (s) & 6480 & 6668 & 2740 & 7440 & 5840 & 11904 & 5300 & 21748 \\
\hline Ascent rate $(\mathrm{m} / \mathrm{s})$ & 0,02 & 0,02 & 0,04 & 0,02 & 0,03 & 0,02 & 0,03 & 0,01 \\
\hline Descent rate $(\mathrm{m} / \mathrm{s})$ & 0,09 & 0,11 & 0,11 & 0,21 & 0,22 & 0,29 & 0,14 & 0,30 \\
\hline Average water temperature during the dive $\left({ }^{\circ} \mathrm{C}\right)$ & $10,3 \pm 0,3$ & $10,3 \pm 0,2$ & $10,1 \pm 0,2$ & $9,6 \pm 0,2$ & $15,2 \pm 0,7$ & $15,2 \pm 0,9$ & $9,4 \pm 0,4$ & $9,5 \pm 0,4$ \\
\hline Maximum water temperature during the dive $\left({ }^{\circ} \mathrm{C}\right)$ & 10,8 & 10,8 & 10,8 & 10,8 & 19,6 & 22,8 & 12,4 & 11,2 \\
\hline Minimum water temperature during the dive $\left({ }^{\circ} \mathrm{C}\right)$ & 8 & 8,8 & 9,6 & 8,8 & 14,8 & 14,4 & 8,8 & 8,8 \\
\hline Water temperature at maximum diving depth $\left({ }^{\circ} \mathrm{C}\right)$ & 10 & 10 & 10 & 10,4 & 15,2 & 14,8 & 9,6 & 9,2 \\
\hline Average heart rate during the dive (bpm) & $87 \pm 18$ & $90 \pm 19$ & $94 \pm 11$ & $84 \pm 20$ & $88 \pm 19$ & $88 \pm 21$ & $93 \pm 22$ & $80 \pm 18$ \\
\hline Average heart rate during the ascent (bpm) & $81 \pm 14$ & $84 \pm 14$ & $91 \pm 9$ & $79 \pm 15$ & $83 \pm 14$ & $84 \pm 17$ & $85 \pm 15$ & $78 \pm 15$ \\
\hline Average heart rate during the descent (bpm) & $113 \pm 6$ & $118 \pm 8$ & $105 \pm 6$ & $124 \pm 9$ & $127 \pm 8$ & $144 \pm 9$ & $129 \pm 11$ & $131 \pm 11$ \\
\hline Maximum heart rate during the dive (bpm) & 144 & 137 & 120 & 142 & 143 & 168 & 149 & 158 \\
\hline Depth at maximum heart rate $(\mathrm{m})$ & 133,17 & 149,37 & 97,07 & 177,11 & 151,05 & $\begin{array}{l}204,69 \\
194,12\end{array}$ & $\begin{array}{l}143,59 \\
147,16\end{array}$ & 251,67 \\
\hline Minimum heart rate (bpm) & 58 & 58 & 71 & 52 & 62 & 57 & 60 & 53 \\
\hline Heart rate at maximum depth (bpm) & 137 & 128 & 109 & 140 & 140 & 159 & 131 & 158 \\
\hline Percentage over maximum heart rate $(\%)$ & 81 & 76 & 64 & 83 & 83 & 94 & 78 & 93 \\
\hline
\end{tabular}

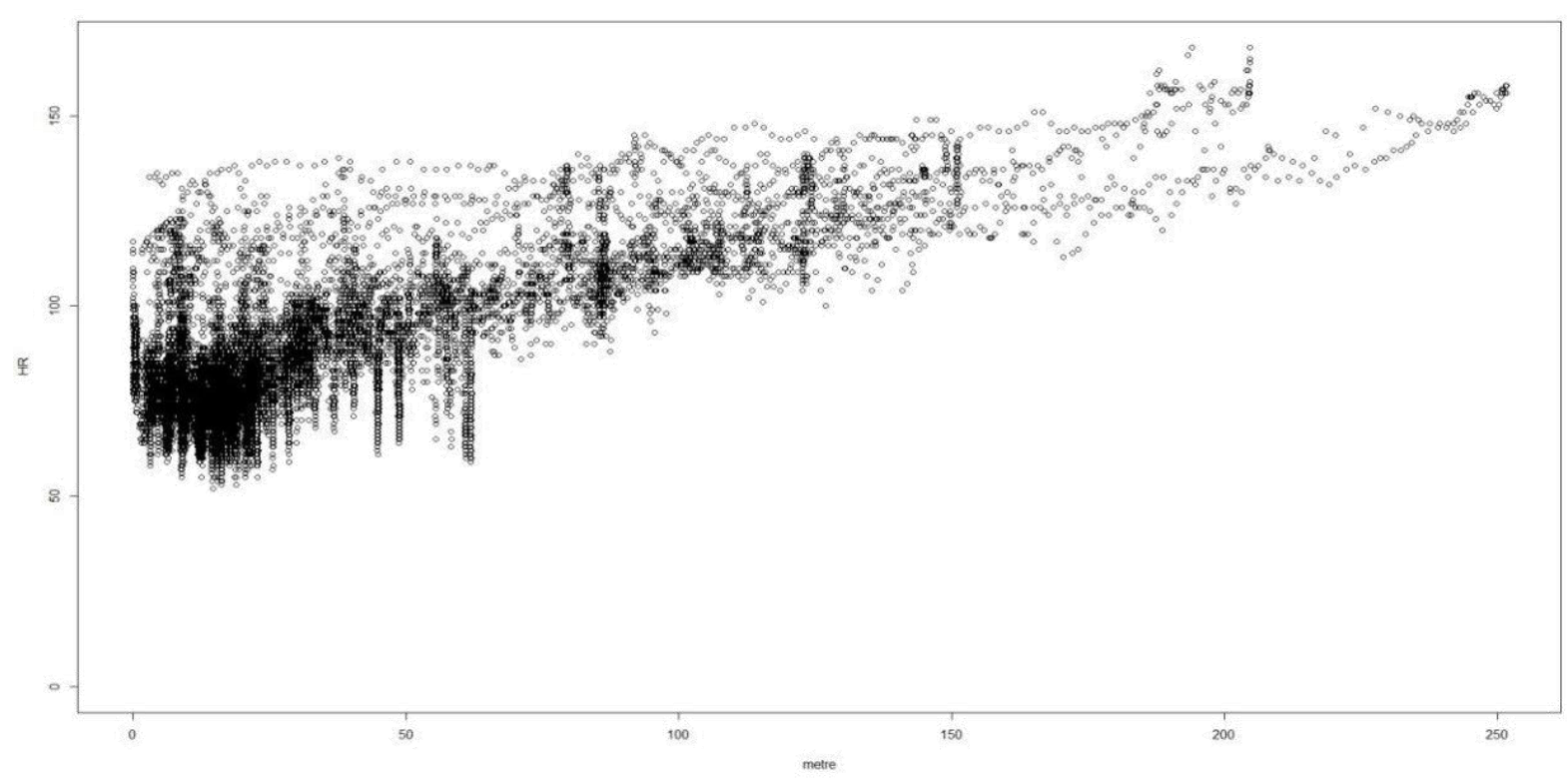

Figure 5. Linear regression analysis to explain the association between HR and depth. 


\section{Discussion}

The average descending heart rate increases with increasing depth. During the first dive to the source of the Gorgazzo, where a depth of 99.18 meters was reached, the average descending heart frequency is $105 \pm 6 \mathrm{bpm}$.

During the second dive where the depth reached is 134.7 meters, we find an average descending heart frequency of $113 \pm 6 \mathrm{bpm}$. The third dive reaches a depth of 150.32 meters and it is possible to observe a further increase in the descending average heart frequency that rises to 118 $\pm 8 \mathrm{bpm}$. The figure still increases if you observe the last dive made at Gorgazzo, where the diver reached the depth of 179.38 meters and an average descending heart rate of $124 \pm 9 \mathrm{bpm}$. In diving in Vrelo Une we observe an average descending frequency of $129 \pm 11 \mathrm{bpm}$ and a depth of 149.36 meters and an average descending frequency of $127 \pm$ $8 \mathrm{bpm}$ at a depth of 151.29 meters, during the dive in the depth of 204.71 meters the average descending heart rate is $144 \pm 9 \mathrm{bpm}$. Finally when the diver reached the depth of 251,67 meters had an average descending heart rate of $131 \pm 11 \mathrm{bpm}$.

In this last case the change in the trend of the average heart rate compared to the depth could be due to other ambiental factors.

The average ascending heart rate does not seem to be related in any evident way to the immersion depth, while the maximum heart rate reached also seems to increase with the immersion depth, in accordance with what has been observed in the average descending frequency. Another physiological phenomenon that can be observed is related to the depth in which is situated the maximum heart rate. At 99.18 meters deep, the frequency peak is detected during the ascent to the depth of 97.07 meters. At 179.38 meters deep, the peak is detected during the ascent to 177.11 meters. Similarly, at the depths of 149.36 and 204.71 meters, the frequency peak is detected during the ascent to 147.16 and 194.12 meters. At the depth of 251.67 meters the extent of the phenomenon seems reduced, with a detection of the frequency peak at 251.59 meters. The observation of this phenomenon could be explained by a delay in adapting the cardiovascular system to the increase in depth. If we observe the average ascending and descending speeds of the dives, we can easily see how the descending speeds in the source of Vrelo Une are greater than those recorded at the source of the
Gorgazzo. In the Gorgazzo dives we find in fact average descent speeds of: $0.09 ; 0.11 ; 0.11 ;$ and 0.21 $\mathrm{m} / \mathrm{s}$. In Vrelo Une, on the other hand, the observable average descent speeds are: $0.22 ; 0.29 ; 0.14 ; 0.30$ $\mathrm{m} / \mathrm{s}$.

This aspect is attributable to the different hydrogeological conformations of the siphons of the two sources. In fact, the Gorgazzo has very narrow passages and a less regular downward trend, interrupted several times by sections going up or flat, while the source of Vrelo Une is formed by a very wide siphon that tends to not change its descent, at least to the topography depth to date. Ascent rates, on the other hand, are influenced not only by the shape of the siphon but also by the physiological decompression times, which undergo an increase based on duration and depth of immersion. These average ascent speeds range from $0.04 \mathrm{~m} / \mathrm{s}$, the fastest detected from the depth of 99.18 meters, to $0.01 \mathrm{~m} / \mathrm{s}$, the slowest detected from the depth of 251.67 meters.

The differences in dive times are equally attributable to the hydrogeological conformation and have for the Gorgazzo source a longer dive time of about 30 minutes. As regards the water temperature we find similar averages except for two dives in Vrelo Une which have an average temperature of $15.2 \pm, 7^{\circ}$ $\mathrm{C}$ and $15.2 \pm 0.9^{\circ} \mathrm{C}$.

\section{Conclusions}

The results of this study indicate an increase in the average heart rate as the immersion depth increases, with an increase of $0.40 \mathrm{bpm}$ per diving meter. This result is in line with what has been observed by other previous studies, in which an increase in heart rate during the dive was found, though the results could be influenced by the experimental situation. Following this study, it is therefore possible to affirm that the heart rate, during dives at very high depths in caves, is directly influenced by the depth of immersion, increasing in relation to depth. Future studies will have to take into account the water temperature, the speed of the currents, the descent rate and possibly the type of mixture used for the dive (in case of use of a mixture of gases) as well as heart rate variability. This study is related to the studies of human physiology in extreme environments that are being carried out by the authors. These studies aim to investigate the physiology and metabolic of a human being engaged in 
extreme performance and extreme environments, with a direct and non-laboratory analysis.

\section{References}

[1] E. Marongiu, A. Crisafulli, G. Ghiani, S. Olla, S. Roberto, M. Pinna, M. Pusceddu, G. Palazzolo, I. Sanna, A. Concu, \& F. Tocco, Cardiovascular responses during free-diving in the sea, International Journal of Sports Medicine, 36 (2015) 297-301.

\section{https://doi.org/10.1055/s-0034-1389969}

[2] S.R. Schirato, I. El-Dash, V. El-Dash, J.E. Natali, P.N. Starzynski, \& J.G. Chaui-Berlinck, Heart rate variability changes as an indicator of decompression-related physiological stress, Undersea \& Hyperbaric Medicine : Journal of the Undersea and Hyperbaric Medical Society, Inc, 45 (2018) 173-182.

https://doi.org/10.22462/03.04.2018.4

[3] Y. Noh, H.F. Posada-Quintero, Y. Bai, J. White, J.P. Florian, P.R. Brink, \& K.H. Chon, Effect of Shallow and Deep SCUBA Dives on Heart Rate Variability, Frontiers in Physiology, 9 (2018) 110.

https://dx.doi.org/10.3389\%2Ffphys.2018.0011 $\underline{0}$

[4] C.M. House, A.M. Shaw, D.G. Roiz de Sa, Rebreather Unit to Prolong Underwater Survival Time, Aerospace Medicine and Human Performance, 86 (2015) 1028-1033. https://doi.org/10.3357/amhp.4267.2015

[5] J.D. Schipke, \& M. Pelzer, Effect of immersion, submersion, and scuba diving on heart rate variability, British Journal of Sports Medicine, 35 (2001) 174-180.

https://dx.doi.org/10.1136\%2Fbjsm.35.3.174

[6] B.E. Walker, K. Tetzlaff, C.M. Muth, K. Paulat, \& H. Hebestreit, SCUBA-Dive-Related Changes in Heart Rate in Children, Pediatric Exercise Science, 23 (2011) 388-398.

https://doi.org/10.1123/pes.23.3.388

[7] F. Molenat, A. Boussuges, A. Grandfond, J.C. Rostain, J.M. Sainty, C. Robinet, F. GALLAND, J.L. Meliet, Haemodynamic effects of hyperbaric hyperoxia in healthy volunteers: an echocardiographic and Doppler study, Clinical Science, $106 \quad$ (2004) 389-395. https://doi.org/10.1042/CS20030293

[8] F. Chouchou, V. Pichot, M. Garet, J.C. Barthélémy, \& F. Roche, Dominance in cardiac parasympathetic activity during real recreational
SCUBA diving, European Journal of Applied Physiolog, $106 \quad$ (2009) 345-352. https://doi.org/10.1007/s00421-009-1010-0

[9] E. Barbosa, J.M. García-Manso, J.M. MartínGonzález, S. Sarmiento, F.J. Calderón, \& M.E. Da Silva-Grigoletto, Effect of hyperbaric pressure during scuba diving on autonomic modulation of the cardiac response: application of the continuous wavelet transform to the analysis of heart rate variability, Military Medicine, 175 (2010) 61-64.

https://doi.org/10.7205/MILMED-D-02-0808

[10] J. Hansel, K. Tetzlaff, D. Axmann, A.M. Niess, \& C. Burgstahler, Effect of simulated dives on diastolic function in healthy men, European Journal of Applied Physiology, 112 (2012) 193199.

https://doi.org/10.1007/s00421-011-1953-9

[11] C. Marabotti, A. Scalzini, D. Menicucci, M. Passera, R. Bedini, \& A. L'abbate, Cardiovascular changes during SCUBA diving: an underwater Doppler echocardiographic study, Acta Physiologica, $209 \quad$ (2013) 62-68. https://doi.org/10.1111/apha.12112

[12] G. Bosco, E. De Marzi, P. Michieli, H.R. Omar, E.M. Camporesi, J. Padulo, A. Paoli, D. Mangar, M. Schiavon, 12-lead Holter monitoring in diving and water sports: a preliminary investigation, Diving and Hyperbaric Medicine, 44 (2014) 202207.

[13] F. Biorci, G. Cugliari, M. Lucchese, \& M. Ivaldi, Effects of nutritional intake on performance in master athletes during an extreme ultra-trail, Journal of Human Sport and Exercise, 15 (2019) 1-8.

https://doi.org/10.14198/jhse.2020.154.07

\section{Acknowledgement}

The authors wish to thank the professional cave diver Luigi Casati for having courageously participated in the expeditions and for allowing the use of his physiological data.

\section{Funding}

This study was not funded by any grant

\section{Conflict of interest}

The authors declare that they have no actual or potential conflict of interest, including 
financial, personal or other relationships with people or organizations that could have inappropriately influenced this work.

\section{Informed consent}

All participants gave written informed consent to participate in this study.

\section{About The License}

(C) The author(s) 2020. The text of this article is open access and licensed under a Creative Commons Attribution 4.0 International License 